\section{Prevalência de exposições ocupacionais de cirurgiões-dentistas e auxiliares de consultório dentário a material biológico}

\author{
Prevalence of occupational exposures \\ to potentially infectious materials among \\ dentists and dental assistants
}

Leila Posenato Garcia 1

Vera Lúcia Guimarães Blank 2

\author{
1 Programa de Pós-graduação \\ em Epidemiologia, \\ Universidade Federal \\ de Pelotas, Pelotas, Brasil. \\ 2 Programa de Pós-graduação \\ em Saúde Pública, \\ Universidade Federal \\ de Santa Catarina, \\ Florianópolis, Brasil. \\ Correspondência \\ L. P. Garcia \\ Programa de Pós-graduação \\ em Epidemiologia \\ Centro de Ciências da Saúde, \\ Universidade Federal \\ de Pelotas. Rua Presidente \\ Coutinho 316, apto. 1101, \\ Florianópolis, SC \\ 88015-230, Brasil. \\ leilapg@matrix.com.br
}

\section{Abstract}

Dentists and dental assistants work in conditions that favor the occurrence of occupational exposures to potentially infectious materials. The aims of this study are: to determine the prevalence of occupational exposures throughout professional life and in the previous year, to identify the circumstances of exposures, and to verify if there exists a relationship between their occurrence and the use of personal protective equipment. 289 dentists and 104 dental assistants from the city of Florianópolis, Brazil, participated in this study. Data were collected through self-report questionnaires. The prevalence of occupational exposures throughout professional life was higher among dentists (94.5\%) than dental assistants (80.8\%), while in the previous year it was similar between dentists (39.1\%) and assistants (39.4\%). However, considering the exposures in the previous year, percutaneous injuries were more frequent among assistants (95.2\%) than dentists (60.7\%). Consistent use of protective eyewear was statistically associated with less splashes in the eyes in dentists $(p=0,004)$. Education is recommended to reduce the frequency of occupational exposures in the study population.

Occupational Accidents; Occupational Exposure; Occupational Health; Dental Staff

\section{Introdução}

As condições de trabalho dos cirurgiões-dentistas e auxiliares de consultório dentário fazem com que eles estejam expostos a uma grande variedade de microrganismos presentes especialmente no sangue, na saliva e nas vias aéreas respiratórias dos pacientes. O risco de exposição era conhecido desde a década de 1930 , contudo tomavam-se poucas medidas visando a evitar a transmissão de agentes patogênicos. Na década de 1980, com o aparecimento da AIDS, o temor do contato com seu agente etiológico, o HIV, acabou sendo um motivador para a adoção de medidas de controle de infecção na prática odontológica 1 . A partir de então as questões relativas ao controle de infecção e às normas de biossegurança receberam maior atenção por parte dos profissionais da odontologia. Passou a haver maior preocupação com a transmissão de doenças do profissional para seus familiares e pacientes, entre diferentes pacientes, e do paciente para o profissional.

Em 1987, o Centers for Disease Control and Prevention (CDC), dos Estados Unidos, criou as Precauções Universais, definidas como um conjunto de precauções para prevenir a exposição dos trabalhadores dos serviços de saúde a patógenos transmitidos pelo sangue. O termo Precauções Universais deve-se à indicação de seu emprego no atendimento de todos os pacientes, já que nem todos os portadores des- 
ses patógenos podem ser identificados previamente à realização de um procedimento invasivo. Em 1996, foram elaboradas as Precauções Padrão, expandindo as Precauções Universais e incorporando princípios de isolamento das substâncias corporais, sendo aplicadas ao contato com sangue, todos os fluidos, excreções e secreções (exceto suor) - independentemente de estas conterem sangue visível -, pele não intacta e membranas mucosas. Como na odontologia a saliva sempre foi considerada um material potencialmente infectante, não existe diferença prática entre Precauções Universais e Precauções Padrão, já que ambas incluem o uso de equipamentos de proteção individual - luvas, jaleco, óculos de proteção, máscara e gorro -, a fim de prevenir o contato da pele e membranas mucosas com material biológico dos pacientes 2 . As orientações do Ministério da Saúde do Brasil para o controle de infecção na prática odontológica incorporaram os conceitos das Precauções Universais e Precauções Padrão ${ }^{1 .}$

Incidente de exposição ocupacional pode ser definido como “(...) contato de mucosa ocular, outra membrana mucosa, pele não-intacta ou contato parenteral com sangue ou outros materiais potencialmente infectantes que pode resultar do desempenho das funções de um trabalhador" 3 (p. 293). Evitar exposições ocupacionais é a forma de prevenção primária da transmissão de patógenos sangüíneos - como o HBV (vírus da hepatite B), HCV (vírus da hepatite C) e HIV - no ambiente odontológico. Essas exposições podem ocorrer através de lesões percutâneas (perfuração ou corte da pele íntegra) e do contato de sangue, tecidos, ou fluidos corporais potencialmente infectantes com as mucosas ocular, nasal, bucal ou pele não íntegra 2 .

No atendimento odontológico, o uso de instrumentos rotatórios e ultra-sônicos favorece a ocorrência de respingos, e a rotina de trabalho com instrumentos perfurocortantes num campo restrito de visualização eleva o risco de lesões percutâneas 4 . A posição dentista/paciente e dos equipamentos no consultório odontológico também pode contribuir para a ocorrência de acidentes 5 .

Este trabalho tem como objetivos: (1) determinar a prevalência das exposições ocupacionais a material biológico do paciente ao longo da vida profissional e no ano anterior ao estudo em uma amostra de cirurgiões-dentistas e auxiliares de consultório dentário do $\mathrm{Mu}$ nicípio de Florianópolis, Santa Catarina, Brasil; (2) identificar os tipos de exposição e os instrumentos, procedimentos e partes do corpo nelas envolvidos; (3) verificar se existe associação entre o uso de equipamentos de proteção individual e a ocorrência dessas exposições.

\section{Métodos}

A população deste estudo transversal constituiu-se de 1.272 cirurgiões-dentistas, domiciliados no Município de Florianópolis, capital do Estado de Santa Catarina, localizado na Região Sul do Brasil, em maio de 2003. Acrescentem-se a esse número os auxiliares de consultório dentário desses profissionais. O tamanho da amostra foi dimensionado para detectar uma prevalência de $60 \%$ no que se refere a acidentes resultantes de exposição ocupacional a material biológico no ano anterior, apresentando margem de erro de $5 \%$, com base em dados da literatura 6 . O valor calculado no programa Epi Info versão 6.0 (Centers for Disease Control and Prevention, Atlanta, Estados Unidos), com nível de confiança de 95\%, foi 286 cirurgiões-dentistas. Realizou-se amostragem probabilística sistemática a partir da listagem em ordem alfabética dos profissionais registrados no Conselho Regional de Odontologia de Santa Catarina (CRO/SC) e solicitou-se ao CRO/SC uma lista de endereços dos 360 selecionados, para haver um número maior que compensasse os sujeitos que fossem excluídos da amostra, mais as perdas e recusas. Foram excluídos da amostra 34 cirurgiões-dentistas que não realizavam atividade clínica, que haviam se aposentado, que não atuavam no Município de Florianópolis ou que se encontravam em período de licença. Dessa forma, 326 profissionais foram contatados e receberam o questionário da pesquisa.

Considerando o fato de que nem todas as pessoas que trabalham como auxiliares de consultório dentário estão registradas no $\mathrm{CRO} / \mathrm{SC}$, não foi possível estimar o tamanho da amostra a partir do tamanho da população, que era desconhecido. Em virtude disso, a amostra de auxiliares de consultório dentário foi formada por aqueles que trabalhavam com os cirurgiõesdentistas selecionados. Além disso, alguns destes poderiam relutar em permitir a participação de seu auxiliar de consultório dentário em um estudo do qual não estariam participando, especialmente considerando que o estudo trata da saúde do trabalhador, pela qual eles também são responsáveis.

Os dados foram coletados por meio de questionário auto-aplicável padronizado, previamente testado com cirurgiões-dentistas e auxiliares de consultório dentário que não faziam parte da amostra. O questionário utilizado é composto por três partes. A primeira se refere 
a características demográficas (idade, sexo) e de formação profissional para cirurgiões-dentistas (ano de conclusão do curso de odontologia, maior titulação, especialidade, realização de atividade de docência, realização de cursos de atualização/aperfeiçoamento) e auxiliares de consultório dentário (grau de escolaridade, realização de curso de formação de auxiliar de consultório dentário). A segunda, comum para cirurgiões-dentistas e auxiliares de consultório dentário, inclui perguntas relacionadas à jornada de trabalho, ao uso dos equipamentos de proteção individual, à vacinação contra a hepatite B e aos acidentes com exposição a material biológico durante toda a vida profissional e no ano anterior ao estudo. A terceira parte está relacionada aos acidentes com exposição a material biológico. Aqueles que responderam ter sofrido esse tipo de acidente no último ano responderam, em relação ao acidente mais recente, a perguntas que incluíam o tipo de acidente (lesão percutânea ou respingo nas mucosas), tipo de material biológico envolvido (sangue, saliva ou outro), parte do corpo afetada, instrumento envolvido, procedimento que estava sendo realizado e equipamentos de proteção individual que estavam sendo utilizados no momento do acidente.

Inicialmente, os 326 cirurgiões-dentistas e seus respectivos auxiliares de consultório dentário que fizeram parte da amostra foram contatados por telefone para agendar um horário para entrega do questionário. No momento da entrega, os pesquisados que aceitaram participar da pesquisa foram informados de que a pesquisadora principal (L.P.G.) retornaria após uma semana para recolher o questionário preenchido. Foram consideradas perdas os casos de não-resposta após três visitas da pesquisadora principal na tentativa de recolher os questionários.

Os profissionais que forneceram as informações não foram identificados nos questionários, o que possibilitou a manutenção do anonimato dos participantes. O estudo foi realizado de acordo com os princípios éticos que constam na Resolução 196/1996 do Conselho Nacional de Saúde. A coleta dos dados foi iniciada apenas após o recebimento do parecer favorável fornecido pelo Comitê de Ética na Pesquisa com Seres Humanos (CEPSH) da Universidade Federal de Santa Catarina (projeto 043/2004).

Foi realizada a descrição das variáveis demográficas e ocupacionais, da prevalência de exposições ocupacionais a material biológico durante a vida profissional e no último ano, bem como das características das lesões percutâneas no ano anterior, entre cirurgiões-dentistas e auxiliares de consultório dentário. $\mathrm{O}$ teste exato de Fischer foi utilizado para testar a associação entre a ocorrência de exposição ocupacional a material biológico no ano anterior e variáveis demográficas e comportamentais na amostra de cirurgiões-dentistas. Quando a variável de exposição apresentava mais de duas categorias, foi utilizado o teste do quiquadrado. $\mathrm{O}$ teste exato de Fischer também foi utilizado para avaliar a associação entre o uso constante de equipamentos de proteção individual e a ocorrência de acidentes resultantes de exposição ocupacional a material biológico, atingindo as partes do corpo que são protegidas pelos respectivos equipamentos de proteção individual, entre a população estudada. As análises estatísticas foram realizadas com o programa Epi Info versão 6.0. Foi adotado o nível de significância $\mathrm{p} \leq 0,05$ e intervalo de confiança de $95 \%$.

\section{Resultados}

Foram entregues questionários a 326 cirurgiões-dentistas, 289 dos quais responderam à investigação, resultando em uma taxa de resposta de $88,7 \%$. Considerando que, dos $289 \mathrm{ci}-$ rurgiões-dentistas respondentes, $41 \%$ declararam realizar o trabalho na maior parte do tempo a quatro mãos (com auxiliar de consultório dentário), era esperada uma amostra de 118 auxiliares de consultório dentário, no entanto foram obtidas as respostas de 104 auxiliares de consultório dentário, indicando uma taxa de resposta de $88,1 \%$.

A idade média dos cirurgiões-dentistas pesquisados é 39,2 anos (25-73) e a média de anos desde a graduação é 16,0 (2-47). Quase metade deles $(46,0 \%)$ tem como maior titulação o curso de graduação. A proporção dos sexos é similar à mesma proporção na população de cirurgiões-dentistas. Dentre os auxiliares de consultório dentário pesquisados, a idade média é 28,4 anos (17-48), a média de anos de trabalho é $6,2(1-28)$ e a maioria tem pelo menos segundo grau completo, mas menos da metade relatou ter realizado curso de formação de auxiliar de consultório dentário.

Outras variáveis demográficas e ocupacionais estão apresentadas na Tabela 1. A distribuição entre os sexos é similar entre os cirurgiões-dentistas, enquanto entre os auxiliares de consultório dentário observa-se uma predominância acentuada do sexo feminino. A maior parte dos cirurgiões-dentistas e auxiliares de consultório dentário declarou trabalhar até oito horas por dia e até cinco dias por semana. Na Tabela 1 também estão apresentadas as pre- 
Variáveis demográficas e ocupacionais, prevalência das exposições ocupacionais a material biológico ocorridas durante a vida profissional e no ano anterior na amostra de cirurgiões-dentistas e auxiliares de consultório dentário. Florianópolis, Santa Catarina, Brasil.

\begin{tabular}{|c|c|c|c|c|}
\hline \multirow[t]{2}{*}{ Variáveis } & \multicolumn{2}{|c|}{ Cirurgiões-dentistas } & \multicolumn{2}{|c|}{$\begin{array}{c}\text { Auxiliares de consultório } \\
\text { dentário }\end{array}$} \\
\hline & $\mathrm{n}$ & $\%$ & $n$ & $\%$ \\
\hline \multicolumn{5}{|l|}{ Sexo } \\
\hline Feminino & 148 & 51,2 & 101 & 97,1 \\
\hline Masculino & 141 & 48,8 & 3 & 2,9 \\
\hline \multicolumn{5}{|l|}{ Idade (anos) } \\
\hline$<30$ & 52 & 18,1 & 62 & 61,4 \\
\hline $30-39$ & 109 & 37,8 & 30 & 29,7 \\
\hline$\geq 40$ & 127 & 44,1 & 9 & 8,9 \\
\hline \multicolumn{5}{|l|}{ Horas de trabalho por dia } \\
\hline$\leq 4$ & 33 & 11,5 & 5 & 4,8 \\
\hline $5-8$ & 195 & 67,9 & 85 & 81,7 \\
\hline$\geq 9$ & 59 & 20,6 & 14 & 13,5 \\
\hline \multicolumn{5}{|c|}{ Dias de trabalho por semana } \\
\hline $1-5$ & 271 & 94,4 & 95 & 91,3 \\
\hline$\geq 6$ & 16 & 5,6 & 9 & 8,7 \\
\hline \multicolumn{5}{|c|}{ Horas de trabalho por semana } \\
\hline$\leq 20$ & 45 & 15,7 & 5 & 4,8 \\
\hline $21-40$ & 181 & 63,3 & 80 & 76,9 \\
\hline$\geq 41$ & 60 & 21,0 & 19 & 18,3 \\
\hline \multicolumn{5}{|c|}{ Freqüência de pausas durante o trabalho } \\
\hline Entre cada paciente & 65 & 24,1 & 22 & 22,4 \\
\hline Quando cansado & 26 & 9,6 & 7 & 7,1 \\
\hline Uma vez por turno & 86 & 31,9 & 42 & 42,9 \\
\hline Não faz pausa & 93 & 34,4 & 27 & 27,6 \\
\hline \multicolumn{5}{|c|}{$\begin{array}{l}\text { Acidente resultante de exposição a material } \\
\text { biológico na vida profissional }\end{array}$} \\
\hline Sim & 273 & 94,5 & 84 & 80,8 \\
\hline Não & 16 & 5,5 & 20 & 19,2 \\
\hline \multicolumn{5}{|c|}{$\begin{array}{l}\text { Acidente resultante de exposição a material } \\
\text { biológico no ano anterior }\end{array}$} \\
\hline Sim & 113 & 39,1 & 41 & 39,4 \\
\hline Não & 139 & 48,1 & 51 & 49,0 \\
\hline Não sabe/não lembra & 37 & 12,8 & 12 & 11,5 \\
\hline
\end{tabular}

Nota: os valores $\mathrm{n}$ e as porcentagens se referem ao número de observações válidas para cada variável. 
valências de exposições ocupacionais em toda a vida profissional e no ano anterior para o grupo em estudo. A prevalência de exposições ao longo da vida profissional foi maior entre os cirurgiões-dentistas, enquanto a prevalência de exposições no ano anterior foi similar entre cirurgiões-dentistas e auxiliares de consultório dentário, respectivamente $39,1 \%$ e $39,4 \%$. Dentre os auxiliares de consultório dentário que relataram ter sofrido exposição ocupacional no ano anterior, $92,5 \%$ e $7,5 \%$ indicaram ter sofrido lesão percutânea e respingo, respectivamente. Dentre os cirurgiões-dentistas que relataram ter sofrido exposição ocupacional no ano anterior, $60,7 \%$ e $39,3 \%$ indicaram ter sofrido lesão percutânea e respingo, respectivamente.

A Tabela 2 apresenta as características das lesões percutâneas no ano anterior em cirurgiões-dentistas e auxiliares de consultório dentário. Entre os auxiliares de consultório dentário, 85,7\% das lesões percutâneas ocorreram após o atendimento a pacientes, durante limpeza do instrumental. Nos cirurgiões-dentistas o mesmo procedimento esteve envolvido em $17,7 \%$ das lesões percutâneas.

Foram registrados 42 respingos no ano anterior em cirurgiões-dentistas e três em auxiliares de consultório dentário. Nos cirurgiõesdentistas, $88,1 \%$ dos respingos atingiram os olhos, sendo $32,4 \%$ durante procedimentos de restauração, 21,6\% durante profilaxia e 21,6\% durante raspagem periodontal. Saliva sem sangue visível foi o material biológico envolvido em $89,2 \%$ desses respingos.

A associação entre ocorrência de exposição ocupacional no ano anterior em cirurgiõesdentistas e algumas variáveis demográficas e comportamentais está apresentada na Tabela 3. Idade, maior titulação e uso constante de óculos de proteção foram estatisticamente associados $(\mathrm{p}<0,05)$ à ocorrência de acidentes com exposição a material biológico do paciente no ano anterior em cirurgiões-dentistas.

Para os auxiliares de consultório dentário, não foi observada associação entre ocorrência de lesões percutâneas e as seguintes variáveis: idade, anos de trabalho, escolaridade, realização de curso de formação e uso de equipamentos de proteção individual. Entre cirurgiõesdentistas e auxiliares de consultório dentário também não foi encontrada associação entre a ocorrência de exposições ocupacionais e as variáveis: horas de trabalho por dia, dias de trabalho por semana, horas de trabalho por semana e freqüência de pausas durante o trabalho. Entre os cirurgiões-dentistas, a realização de trabalho a quatro mãos (com auxiliar) não foi associada à ocorrência de exposições ocupacionais.
A Tabela 4 apresenta a freqüência do uso dos equipamentos de proteção individual no momento das exposições ocupacionais. As luvas, que são os equipamentos de proteção individual mais usados pelos cirurgiões-dentistas, estavam sendo utilizadas em todos os casos de respingo e em 90,8\% dos casos de lesões percutâneas. Entretanto, elas não estavam sendo usadas em cinco casos de lesões percutâneas nos dedos, que ocorreram durante procedimentos de limpeza do instrumental. Os cirurgiões-dentistas estavam usando máscara, óculos e jaleco de mangas longas em $87,7 \%$, $66,2 \%$ e $40 \%$ das lesões percutâneas, respectivamente. Quando sofreram respingos, 95,2\% dos cirurgiões-dentistas estavam usando máscara e $45,2 \%$ jaleco de mangas longas, mas apenas $26,2 \%$ estavam usando óculos de proteção. Dentre os auxiliares de consultório dentário que sofreram lesão percutânea, 95,6\% estavam usando luvas, apesar de poucos estarem usando os outros equipamentos de proteção individual indicados.

Na Tabela 5, está apresentada a associação entre o uso constante de equipamentos de proteção individual e a ocorrência de exposições ocupacionais afetando as partes do corpo passíveis de proteção pelos respectivos equipamentos de proteção individual, entre cirurgiões-dentistas e auxiliares de consultório dentário. A associação entre uso constante de óculos, jaleco e máscara e freqüência de exposições em auxiliares de consultório dentário não foi apresentada por causa do pequeno número de exposições envolvendo as partes do corpo que poderiam ser protegidas com o uso desses equipamentos de proteção individual na amostra. O mesmo se aplica ao uso constante de máscara na amostra de cirurgiões-dentistas. O uso constante de óculos de proteção foi estatisticamente associado com uma menor ocorrência de respingos nos olhos em cirurgiões-dentistas $(\mathrm{p}=$ 0,004). Corroborando esse achado, observou-se que $73,8 \%$ dos cirurgiões-dentistas que sofreram respingos nos olhos não estavam usando óculos de proteção. O uso constante de jaleco com mangas compridas também foi associado com uma menor ocorrência de lesões percutâneas afetando braço e antebraço $(\mathrm{p}=0,034)$.

\section{Discussão}

Os dados deste estudo foram coletados a partir de uma amostra de cirurgiões-dentistas e auxiliares de consultório dentário do Município de Florianópolis, e assim podem não representar a realidade da população de cirurgiões-dentis- 
Características das lesões percutâneas no ano anterior na amostra de cirurgiões-dentistas e auxiliares de consultório dentário. Florianópolis, Santa Catarina, Brasil.

\begin{tabular}{|c|c|c|c|c|}
\hline \multirow[t]{2}{*}{ Variáveis } & \multicolumn{2}{|c|}{ Cirurgiões-dentistas } & \multicolumn{2}{|c|}{$\begin{array}{c}\text { Auxiliares de consultório } \\
\text { dentário }\end{array}$} \\
\hline & $\mathrm{n}$ & $\%$ & $\mathrm{n}$ & $\%$ \\
\hline \multicolumn{5}{|l|}{ Tipo da lesão percutânea } \\
\hline Perfuração & 41 & 63,1 & 31 & 83,8 \\
\hline Arranhão & 18 & 27,7 & 5 & 13,5 \\
\hline Corte & 5 & 7,7 & 1 & 2,7 \\
\hline Mordedura & 1 & 1,5 & - & - \\
\hline \multicolumn{5}{|l|}{ Parte do corpo envolvida } \\
\hline Dedo & 47 & 72,3 & 31 & 83,8 \\
\hline Mão & 3 & 4,6 & 5 & 13,5 \\
\hline Antebraço/Braço & 12 & 23,0 & - & - \\
\hline Nádega & - & - & 1 & 2,7 \\
\hline \multicolumn{5}{|l|}{ Procedimento envolvido } \\
\hline Restauração & 24 & 38,7 & 2 & 5,7 \\
\hline Limpeza do instrumental & 11 & 17,7 & 30 & 85,7 \\
\hline Cirurgia & 8 & 12,9 & - & - \\
\hline Periodontia & 7 & 11,3 & 1 & 2,9 \\
\hline Reencape de agulha & 4 & 6,5 & 2 & 5,7 \\
\hline Ortodontia & 3 & 4,8 & - & - \\
\hline Outro & 5 & 8,1 & - & - \\
\hline \multicolumn{5}{|l|}{ Instrumento envolvido } \\
\hline Broca & 20 & 33,3 & 3 & 8,8 \\
\hline Agulha & 14 & 23,3 & 5 & 14,7 \\
\hline Sonda exploradora & 9 & 15,0 & 19 & 55,9 \\
\hline Lima endodôntica & 5 & 8,4 & 3 & 8,8 \\
\hline Cureta & 5 & 8,4 & 2 & 5,9 \\
\hline Fio ortodôntico & 3 & 5,0 & 1 & 2,9 \\
\hline Outro & 4 & 6,6 & 1 & 2,9 \\
\hline \multicolumn{5}{|l|}{ Material biológico envolvido } \\
\hline Saliva sem sangue visível & 47 & 74,6 & 31 & 86,1 \\
\hline Saliva com sangue visível & 9 & 14,3 & 3 & 8,3 \\
\hline Sangue & 2 & 3,2 & 2 & 5,6 \\
\hline Outro & 5 & 7,9 & - & - \\
\hline
\end{tabular}

Nota: os valores $\mathrm{n}$ e as porcentagens se referem ao número de observações válidas para cada variável.

tas e auxiliares de consultório dentário brasileiros. A amostragem probabilística e a taxa de resposta satisfatória contribuem para a validade interna da amostra de cirurgiões-dentistas, contudo não se pode assegurar a validade interna da amostra de auxiliares de consultório dentário, selecionada de maneira não-probabilística. Apesar disso, os dados fornecem indicações sobre as características da população estudada em relação à ocorrência de exposições ocupacionais a material biológico e o uso de equipamentos de proteção individual.
O delineamento transversal do estudo, com coleta dos dados retrospectivos por meio de questionários auto-aplicáveis, possibilita a ocorrência de viés de memória. Outro tipo de viés comum a esse de delineamento é o de causalidade reversa, já que as informações sobre exposição e desfecho foram coletadas ao mesmo tempo. Conseqüentemente, não se pode afirmar definitivamente, com base nos resultados do presente estudo, que o uso de determinados equipamentos de proteção individual protegeu contra a ocorrência de exposições 
Associação entre ocorrência de exposições ocupacionais a material biológico no ano anterior e variáveis demográficas e comportamentais na amostra de cirurgiões-dentistas. Florianópolis, Santa Catarina, Brasil.

\begin{tabular}{|c|c|c|c|c|c|c|}
\hline \multirow[t]{3}{*}{ Variáveis } & \multicolumn{4}{|c|}{ Exposição ocupacional no ano anterior } & \multirow[t]{3}{*}{$\mathrm{n}^{\star}$} & \multirow[t]{3}{*}{ p } \\
\hline & & & & & & \\
\hline & $\mathrm{n}$ & $\%$ & $\mathrm{n}$ & $\%$ & & \\
\hline \multicolumn{7}{|l|}{ Sexo } \\
\hline Feminino & 59 & 39,9 & 89 & 60,1 & & \\
\hline Masculino & 54 & 38,3 & 87 & 49,9 & 289 & $0,439 * *$ \\
\hline \multicolumn{7}{|l|}{ Faixa etária (anos) } \\
\hline$<30$ & 30 & 57,7 & 22 & 42,3 & & \\
\hline $30-39$ & 40 & 36,7 & 69 & 63,3 & & \\
\hline$\geq 40$ & 42 & 33,1 & 85 & 66,9 & 288 & $0,008^{* \star *}$ \\
\hline \multicolumn{7}{|l|}{ Maior titulação } \\
\hline Graduação & 55 & 41,4 & 78 & 58,6 & & \\
\hline Especialização & 49 & 43,4 & 64 & 56,6 & & \\
\hline Mestrado/Doutorado & 9 & 20,9 & 34 & 79,1 & 289 & $0,028^{\star \star *}$ \\
\hline \multicolumn{7}{|l|}{ Principal especialidade } \\
\hline Clinica geral & 37 & 38,5 & 59 & 61,5 & & \\
\hline Cirúrgica\# & 12 & 42,9 & 16 & 57,1 & & \\
\hline Outras & 63 & 38,4 & 101 & 61,6 & 288 & $0,902^{\star *}$ \\
\hline \multicolumn{7}{|c|}{$\begin{array}{l}\text { Fez curso de atualização/ } \\
\text { aperfeiçoamento nos últimos } 2 \text { anos }\end{array}$} \\
\hline Sim & 72 & 36,5 & 125 & 63,5 & & \\
\hline Não & 45,6 & 45,6 & 49 & 54,4 & 287 & $0,093^{\star *}$ \\
\hline \multicolumn{7}{|c|}{$\begin{array}{l}\text { Fez curso envolvendo } \\
\text { biossegurança nos últimos } 2 \text { anos }\end{array}$} \\
\hline Sim & 26 & 40,0 & 39 & 60,0 & & \\
\hline Não & 87 & 38,8 & 137 & 61,2 & 289 & $0,487^{\star *}$ \\
\hline \multicolumn{7}{|l|}{ Sempre usa luvas } \\
\hline Sim & 103 & 39,2 & 160 & 60,8 & & \\
\hline Não & 10 & 38,5 & 16 & 61,5 & 289 & $0,560^{* *}$ \\
\hline \multicolumn{7}{|c|}{ Sempre usa óculos de proteção } \\
\hline Sim & 59 & 34,3 & 113 & 65,7 & & \\
\hline Não & 54 & 46,2 & 63 & 53,8 & 289 & $0,028^{\star *}$ \\
\hline \multicolumn{7}{|l|}{ Sempre usa máscara } \\
\hline $\operatorname{Sim}$ & 106 & 39,1 & 165 & 60,9 & & \\
\hline Não & 7 & 38,5 & 11 & 61,1 & 289 & $0,596^{* *}$ \\
\hline \multicolumn{7}{|l|}{ Sempre usa jaleco } \\
\hline Sim & 105 & 39,2 & 163 & 60,8 & & \\
\hline Não & 8 & 38,1 & 13 & 61,9 & 289 & $0,558^{\star *}$ \\
\hline \multicolumn{7}{|l|}{ Sempre usa gorro } \\
\hline Sim & 33 & 40,7 & 48 & 59,3 & & \\
\hline Não & 80 & 38,5 & 128 & 61,5 & 289 & $0,410^{* *}$ \\
\hline
\end{tabular}

* Número de observações válidas.

** Teste exato de Fischer.

*** Teste do qui-quadrado.

\# Cirurgia bucomaxilofacial, periodontia ou implantodontia. 
Tabela 4

Freqüência do uso dos equipamentos de proteção individual no momento das exposições ocupacionais, por ocupação e tipo de exposição, na amostra de cirurgiões-dentistas e auxiliares de consultório dentário. Florianópolis, Santa Catarina, Brasil.

\begin{tabular}{|c|c|c|c|c|c|c|}
\hline \multirow{3}{*}{$\begin{array}{l}\text { Equipamentos de proteção individual } \\
\text { usados no momento da exposição }\end{array}$} & \multicolumn{4}{|c|}{ Cirurgiões-dentistas } & \multirow{2}{*}{\multicolumn{2}{|c|}{$\begin{array}{c}\text { Auxiliares de consultório } \\
\text { dentário } \\
\text { Lesão percutânea }\end{array}$}} \\
\hline & \multicolumn{2}{|c|}{ Respingo } & \multicolumn{2}{|c|}{ Lesão percutânea } & & \\
\hline & $\mathrm{n}$ & $\%$ & $\mathrm{n}$ & $\%$ & $n$ & $\%$ \\
\hline Luvas & 42 & 100,0 & 59 & 90,8 & 35 & 95,6 \\
\hline Óculos & 11 & 26,2 & 43 & 66,2 & 5 & 13,5 \\
\hline Máscara & 40 & 95,2 & 57 & 87,7 & 8 & 21,6 \\
\hline Jaleco de mangas longas & 19 & 45,2 & 26 & 40,0 & 10 & 27,0 \\
\hline Gorro & 14 & 33,3 & 22 & 33,8 & 10 & 27,0 \\
\hline Total & 42 & 100,0 & 65 & 100,0 & 37 & 100,0 \\
\hline
\end{tabular}

Tabela 5

Associação entre o uso constante dos equipamentos de proteção individual e ocorrência de exposições ocupacionais de partes do corpo passíveis de proteção pelos respectivos equipamentos de proteção individual, de acordo com a ocupação, nas amostra de cirurgiões-dentistas e auxiliares de consultório dentário. Florianópolis, Santa Catarina, Brasil.

\begin{tabular}{|c|c|c|c|c|c|c|}
\hline \multirow[t]{3}{*}{ Partes do corpo afetadas } & \multirow{3}{*}{$\begin{array}{l}\text { Freqüência do uso constante } \\
\text { de equipamentos de proteção individual }\end{array}$} & \multicolumn{4}{|c|}{ Exposição ocupacional } & \multirow[t]{3}{*}{$p^{*}$} \\
\hline & & & & & & \\
\hline & & $\mathrm{n}$ & $\%$ & $\mathrm{n}$ & $\%$ & \\
\hline \multicolumn{7}{|l|}{ Cirurgiões-dentistas } \\
\hline \multirow[t]{3}{*}{ Dedo, mão } & Sempre usa luvas & & & & & \\
\hline & Não & 3 & 11,5 & 23 & 88,5 & \\
\hline & Sim & 49 & 18,8 & 211 & 81,2 & 0,266 \\
\hline \multirow[t]{3}{*}{ Antebraço, braço } & Sempre usa jaleco de mangas compridas & & & & & \\
\hline & Não & 13 & 8,7 & 137 & 91,3 & \\
\hline & Sim & 4 & 2,9 & 132 & 97,1 & 0,034 \\
\hline \multirow[t]{3}{*}{ Olhos } & Sempre usa óculos de proteção & & & & & \\
\hline & Não & 23 & 19,7 & 94 & 80,3 & \\
\hline & Sim & 14 & 8,1 & 158 & 91,9 & 0,004 \\
\hline \multicolumn{7}{|c|}{ Auxiliares de consultório dentário } \\
\hline \multirow[t]{3}{*}{ Dedo, mão } & Sempre usa luvas & & & & & \\
\hline & Não & 10 & 43,5 & 13 & 56,5 & \\
\hline & Sim & 26 & 32,9 & 53 & 67,1 & 0,244 \\
\hline
\end{tabular}

* Teste exato de Fischer.

Nota: os valores $\mathrm{n}$ e as porcentagens se referem ao número de observações válidas para cada variável. 
ocupacionais a material biológico, uma vez que as pessoas que sofreram esse tipo de exposição podem ter passado a utilizar os equipamentos de proteção individual com maior freqüência após esse evento.

A prevalência de acidentes com exposição ocupacional a material biológico entre cirurgiões-dentistas encontrada no presente estudo ficou abaixo daquela relatada na literatura. Felix et al. 6 conduziram um estudo retrospectivo com 310 dentistas na Escócia e constataram que as lesões percutâneas são comuns na prática odontológica, já que $56 \%$ dos dentistas pesquisados responderam ter sofrido pelo menos uma lesão desse tipo no ano anterior.

Considerando a natureza da investigação, pode-se esperar que os resultados subestimem a prevalência dos acidentes com exposição ocupacional e a não-aderência às medidas de controle de infecção, já que os sujeitos tendem a reportar comportamentos aceitáveis, mesmo quando não os adotam.

$\mathrm{O}$ achado de que a prevalência de lesões percutâneas foi maior entre auxiliares de consultório dentário do que entre cirurgiões-dentistas está de acordo com o trabalho de Kerr \& Blank 7 , que realizaram um estudo prospectivo, com registro diário por trinta dias para verificar a ocorrência de lesões percutâneas em 65 clínicas odontológicas nos Estados Unidos e encontraram um índice anual de lesões de 3,00 para cirurgiões-dentistas e 5,16 para auxiliares de consultório dentário. Atribui-se isso ao fato de os auxiliares realizarem procedimentos de desmonte, limpeza ou descarte dos instrumentos, podendo sofrer lesões após o término do procedimento operatório.

Era esperado observar-se maior prevalência de acidentes resultantes de exposição ocupacional a material biológico entre cirurgiõesdentistas do que entre auxiliares de consultório dentário, porque as exposições ocupacionais na vida são fortemente afetadas pelo tempo de trabalho dos trabalhadores, e os cirurgiões-dentistas tinham uma média de anos desde a graduação (16,0 anos) superior ao tempo de trabalho médio dos auxiliares de consultório dentário (6,8 anos). Possivelmente uma amostra maior, que permitisse o ajuste por tempo de trabalho, revelaria mais exposições ocupacionais entre os auxiliares de consultório dentário.

No Brasil, há relativamente poucas informações a respeito da freqüência e natureza dos acidentes resultantes de exposição ocupacional a material biológico em cirurgiões-dentistas e auxiliares de consultório dentário e sobre a aderência a medidas de proteção individual. Magro-Filho et al. 8 investigaram as medidas de controle de infecção adotadas por 107 dentistas na região de Araçatuba e Birigüi, no Estado de São Paulo. Setenta por cento dos dentistas responderam ter sofrido algum acidente com instrumental cortante em sua vida profissional. Alves-Rezende \& Lorenzato 9 pesquisaram as medidas de prevenção dos riscos biológicos adotadas por 69 odontólogos da região centrooeste do Estado de São Paulo. Pouco mais da metade dos cirurgiões-dentistas $(55,8 \%)$ relatou sempre usar jaleco durante o atendimento de pacientes; 93\% relataram sempre usar máscara; $67,4 \%$ informaram sempre usar óculos de proteção e $52 \%$ indicaram sempre usar gorro. Apenas 30,2\% e 58,2\% dos cirurgiões-dentistas relataram fornecer ao auxiliar de consultório dentário óculos de proteção e jaleco, respectivamente.

No presente estudo, o uso constante de óculos de proteção foi estatisticamente associado com uma menor ocorrência de respingos, e o uso de jaleco de mangas compridas, com uma menor ocorrência de lesões no antebraço e braço em cirurgiões-dentistas $(\mathrm{p}<0,05)$. Esse resultado está de acordo com o de estudos que demonstram que a aderência às medidas de proteção individual promove redução na freqüência de exposições ocupacionais 10 .

O uso de luvas não resultou na redução da ocorrência de lesões percutâneas nos dedos e mãos, porém, durante os procedimentos odontológicos, a contaminação da saliva com sangue é previsível, e o trauma às mãos dos profissionais é comum. O uso de luvas minimiza o potencial para o contato de pele não intacta dos profissionais da odontologia com a saliva contaminada com sangue dos pacientes 11 . As luvas cirúrgicas não impedem a ocorrência de lesões percutâneas, entretanto, se estas ocorrerem, a interferência das luvas reduz a quantidade de material biológico inoculado, podendo reduzir, igualmente, a possibilidade de aquisição de patógenos em alguns casos 12 .

Considerando que, no presente estudo, $81,1 \%$ das lesões percutâneas em auxiliares de consultório dentário e 16,9\% em cirurgiõesdentistas ocorreram durante limpeza do instrumental, sugere-se a implementação de medidas educativas que resultem no reforço do uso de luvas de borracha grossa específicas para essa tarefa.

Acredita-se que o uso de máscaras reduza a ocorrência de respingos nas mucosas nasal e bucal, todavia, neste estudo não houve casos suficientes para confirmar essa associação. $\mathrm{O}$ gorro, apesar de não estar implicado diretamente na prevenção de acidentes com exposição a material biológico, é indicado para uso 
na odontologia, uma vez que impede a deposição de gotículas e partículas no cabelo do profissional, evitando sua contaminação e a contaminação cruzada.

Para que haja proteção ideal do profissional contra exposições ocupacionais, ele deve utilizar todos os equipamentos de proteção individual recomendados em todos os atendimentos. A proporção de sujeitos que usa sempre todos os equipamentos de proteção individual (luvas, óculos de proteção, máscara, jaleco e gorro) é significativamente maior entre cirurgiões-dentistas $(\mathrm{p}<0,05)$. Todavia, como os auxiliares de consultório dentário também exercem funções que não implicam contato direto com material biológico do paciente, como a manipulação de materiais e atividades burocráticas, esses trabalhadores podem ter indicado que nem sempre usam alguns equipamentos de proteção individual, visto que estes não são necessários em algumas situações.

De acordo com Carvalho 13, os auxiliares de consultório dentário são uma categoria profissional em expansão, acompanhando o crescimento da oferta de serviços odontológicos. A utilização de pessoal auxiliar melhora a qualidade da assistência odontológica e aumenta a produtividade dos serviços. Apesar de sua importância na prestação de serviços e de sua participação crescente nas equipes de saúde, chama a atenção a forma precária com que esses profissionais se inserem no mercado de trabalho - muitos começam a trabalhar sem qualquer capacitação e são treinados no próprio serviço, são mal remunerados e não têm estabilidade no emprego. No presente estudo, apenas 34,6\% dos auxiliares de consultório dentário haviam realizado curso de formação. Além disso, a baixa média de anos de trabalho $(6,2)$ é indicativa de elevada rotatividade nessa ocupação.

$\mathrm{O}$ registro de seis acidentes envolvendo a atividade de reencapar agulhas indica a necessidade de treinamento dos cirurgiões-dentistas e auxiliares de consultório dentário no intuito de erradicar práticas inadequadas e reforçar a implementação de medidas de proteção que resultem na redução da ocorrência de acidentes com exposição a material biológico. Levando-se em conta que esses acidentes podem resultar na aquisição de doenças, é fundamental que todos os membros da equipe odontológica conheçam as doenças que podem ser transmitidas e seus modos de transmissão, para que possam se proteger adequadamente. Quando compreendem os motivos da necessidade da adoção de medidas de controle de infecção, as pessoas são mais propensas a aderir 2 .
A realização de curso de atualização/aperfeiçoamento nos últimos dois anos foi indicada por $68,6 \%$ dos cirurgiões-dentistas, entretanto apenas $27,9 \%$ destes haviam realizado curso envolvendo a biossegurança. Do total de cirurgiões-dentistas, apenas $22,5 \%$ indicaram a realização de curso, nos últimos dois anos, sobre o tema. Isso indica que grande parte dos cursos de atualização/aperfeiçoamento oferecidos para cirurgiões-dentistas não está abordando essa questão.

A introdução de módulos sobre biossegurança, não apenas nos cursos de pós-graduação, mas também nos cursos de atualização e aperfeiçoamento em odontologia, é indicada para reforçar os princípios de controle de infecção, incluindo as medidas de proteção pessoal. Essa iniciativa poderia contribuir também para as condições de trabalho dos auxiliares de consultório dentário, já que os cirurgiões-dentistas, como empregadores, têm o dever de fornecer um ambiente de trabalho seguro para seus funcionários, não bastando simplesmente fornecer os equipamentos de proteção individual, mas também assegurar que eles estejam sendo corretamente utilizados.

Epstein et al. 14 relataram uma elevada aderência às medidas de controle de infecção no Canadá, obtida mediante educação continuada e aderência voluntária. Os autores acreditam que a educação continuada dos profissionais da odontologia deve ser direcionada para melhorar seu conhecimento a respeito da transmissão de doenças infecciosas, sendo essa a única maneira pela qual se pode obter a conscientização da necessidade de aderir e a própria aderência às medidas de controle de infecção.

Deve haver uma discussão a respeito dos conteúdos e estratégias pedagógicas a serem empregadas na educação continuada, possibilitando a fixação dos conteúdos relevantes, de modo a resultar em um impacto maior na mudança de comportamento dos trabalhadores. Ademais, também se recomenda a discussão dos processos de trabalho e saúde na prática odontológica.

Bentley \& Sarll 15 salientam que a ausência de evidência de que certa ação terá um resultado mensurável relativo a uma fonte de infecção em particular resulta numa aderência incompleta aos procedimentos de controle de infecção. No entanto, esse não pode ser um motivo para a não-adoção de um procedimento, uma vez que existem diversas doenças com transmissão comprovada durante o atendimento odontológico, como hepatite B, hepatite $\mathrm{C}$ e AIDS.

As possíveis conseqüências das exposições ocupacionais a material biológico na saúde dos 
cirurgiões-dentistas e auxiliares de consultório dentário são difíceis de prever. Sabe-se que o risco de aquisição do HIV, do HBV e do HCV é considerado pequeno na odontologia. Contudo, também se sabe que apenas uma exposição pode ser suficiente para a transmissão, e que o risco é multiplicado pelo número de exposições repetidas 2 . Somando-se isso ao fato de que os patógenos mencionados podem causar doenças com um período de incubação longo, é plausível imaginar que muitos trabalhadores da odontologia possam ser portadores desses patógenos adquiridos ocupacionalmente sem terem conhecimento. Além disso, novas fontes de infecção cruzada aparecem continuamente. Ainda não se têm informações suficientes sobre doenças emergentes - como a variante da doença de Creutzfeldt-Jakob (conhecida como doença da vaca louca) e o vírus do Nilo Ocidental - para mensurar o risco que elas representam na odontologia.

Para pesquisas futuras, sugere-se a coleta de dados de maneira prospectiva, com amostras maiores, para que se possa determinar o risco dos acidentes resultantes de exposição ocupacional a material biológico entre cirurgiões-dentistas e auxiliares de consultório dentário, permitindo comparar diferentes perfis dessas categorias. Também é fundamental avaliar a ocorrência de acidentes antes e após a implementação de um programa visando aperfeiçoar as práticas de controle de infecção em cirurgiões-dentistas e auxiliares de consultório dentário, incluindo treinamento para redução da ocorrência de acidentes resultantes de exposição a material biológico.
Resumo

Os cirurgiões-dentistas e auxiliares de consultório dentário trabalham em condições que favorecem a ocorrência de exposições ocupacionais a material biológico. Os objetivos do presente estudo são: determinar a prevalência de exposições ocupacionais ao longo da vida profissional e no ano anterior a este estudo, identificar as circunstâncias das exposições e verificar se existe relação entre sua ocorrência e o uso de equipamentos de proteção individual. Participaram do estudo 289 dentistas e 104 auxiliares do município de Florianópolis, Santa Catarina, Brasil. Os dados foram coletados por meio de questionário auto-aplicável. A prevalência de exposições ocupacionais na vida profissional foi maior entre os dentistas (94,5\%) do que entre os auxiliares (80,8\%), ao passo que, no ano anterior, foi similar entre dentistas $(39,1 \%)$ e auxiliares $(39,4 \%)$. Todavia, considerando as exposições ocorridas no ano anterior, as lesões percutâneas foram mais freqüentes nos auxiliares (95,2\%) do que nos dentistas (60,7\%). O uso constante de óculos de proteção foi estatisticamente associado com menor ocorrência de respingos nos olhos de dentistas $(p=0,004)$. São recomendadas medidas educativas visando a reduzir a freqüência de exposições ocupacionais na população estudada.

Saúde Ocupacional; Acidentes de Trabalho; Exposição Ocupacional; Recursos Humanos em Odontologia

\section{Colaboradores}

L. P. Garcia e V. L. G. Blank contribuíram na concepção e desenho do estudo. L. P. Garcia realizou a coleta dos dados, a organização do banco de dados e realizou uma primeira versão da análise e redação do trabalho. V. L. G. Blank orientou essas etapas e participou da elaboração final do manuscrito.

\section{Agradecimentos}

As autoras agradecem ao Programa de Pós-graduação em Saúde Pública da Universidade Federal de Santa Catarina, pelo apoio a este trabalho, que é parte da Dissertação de Mestrado em Saúde Pública apresentada por L. P. Garcia. Esta autora agradece à Coordenação de Aperfeiçoamento de Pessoal de Nível Superior (CAPES), pela concessão de bolsa. As autoras agradecem, igualmente, aos professores Dr. Luiz Augusto Facchini e Dr. Marco Aurélio de Anselmo Peres, pelas sugestões de aprimoramento do artigo, e ao Prof. Dr. Sérgio Fernando Torres de Freitas, pelas contribuições ao projeto de pesquisa, bem como a todos os cirurgiões-dentistas e auxiliares de consultório dentário que participaram da pesquisa. 


\section{Referências}

1. Ministério da Saúde. Controle de infecções e a prática odontológica em tempos de AIDS: manual de condutas. Brasília: Ministério da Saúde; 2000.

2. Kohn WG, Collins AS, Cleveland JL, Harte JA, Eklund KJ, Malvitz DM, et al. Guidelines for infection control in dental health-care settings - 2003 . MMWR Recomm Rep 2003; 52:1-66.

3. U.S. Department of Labor. OSHA bloodborne pathogens standards. U.S. Code of Federal Regulations 1997; Title 29 Part 1910 Section 1030:293.

4. Graziano KU, Graziano RW, Rodrigues L, Barros ER. Serviço de odontologia. In: Fernandes AT, Fernandes MOV, Ribeiro Filho N, organizadores. Infecção hospitalar e suas interfaces na área da saúde. São Paulo: Atheneu, 2000. p. 861-81.

5. Ramos-Gomez, F, Ellison J, Greenspan D, Bird W, Lowe S, Gerberding JL. Accidental exposures to blood and body fluids among health cares workers in dental teaching clinics: a prospective study. J Am Dent Assoc 1997; 128:1253-61.

6. Felix DH, Bird AG, Anderson HG, Gore SM, Brettle RP, Wray D. Recent non-sterile inoculation injuries to dental professionals in the Lothian Region of Scotland. Br Dent J 1994; 176:180-4.

7. Kerr SP, Blank LW. Percutaneous injuries among dental health care workers. Gen Dent 1999; 47:14651.

8. Magro-Filho O, Melo MS, Martin SC. Métodos de esterilização, desinfecção e paramentação utilizados pelo cirurgião-dentista e auxiliar no consultório odontológico. Levantamento entre os profissionais. Rev Assoc Paul Cir Dent 1991; 45:58992.
9. Alves-Rezende MCR, Lorenzato F. Avaliação dos procedimentos de prevenção dos riscos biológicos por cirurgiões-dentistas. Rev Assoc Paul Cir Dent 2000; 54:446-54.

10. Wong ES, Stotka JL, Chinchilli VM, Williams DS, Stuart G, Markowitz SM. Are universal precautions effective in reducing the number of occupational exposures among health care workers? JAMA 1991; 265:1123-8.

11. Centers for Disease Control and Prevention. Perspectives in disease prevention and health promotion update: universal precautions for prevention of transmission of human immunodeficiency virus, hepatitis B virus, and other bloodborne pathogens in health-care settings. MMWR Morb Mortal Wkly Rep 1988; 37:377-88.

12. Mast ST, Woolwine JD, Gerberding JL. Efficacy of gloves in reducing blood volumes transferred during simulated needlestick injury. J Infect Dis 1993; 168:1589-92.

13. Carvalho CL. Trabalho e profissionalização das categorias auxiliares em odontologia. In: Ministério da Saúde, organizador. Guia curricular para formação do atendente de consultório dentário para atuar na rede básica do SUS. Brasília: Ministério da Saúde; 1998.

14. Epstein JB, Mathias RG, Bridger DV. Survey of knowledge of infectious disease and infection control practices of dental specialists. J Can Dent Assoc 1995; 61:35-44.

15. Bentley EM, Sarll DW. Improvements in cross-infection control in general dental practice. Br Dent J 1995; 179:19-21.

Recebido em 08/Mar/2005

Versão final reapresentada em 02/Jun/2005 Aprovado em 06/Jul/2005 